\title{
Wind Turbines as Additional Power Supply
}

\author{
Arwa Azhry Mohammed Othman, Rawia Abdalgani, Mubarak Dirar \\ Department of Physics, Sudan University of Science \& Technology, Khartoum, Sudan
}

Correspondence to: Arwa Azhry Mohammed Othman, horia40@gmail.com ; Rawia Abdalgani, rawia_abdalgani@yahoo.com

Keywords: Wind Turbine, Renewable Energy, Generate Electricity, Power Supply

Received: April 19, $2018 \quad$ Accepted: June 25, $2018 \quad$ Published: June 28, 2018

Copyright $\odot 2018$ by authors and Scientific Research Publishing Inc.

This work is licensed under the Creative Commons Attribution International License (CC BY 4.0).

http://creativecommons.org/licenses/by/4.0/

(c) (i) Open Access

\section{ABSTRACT}

Recently, mankind's need for more amount of energy has been increasing day by day, though there is a trend to reduce the usage of the traditional energy source to an energy carrier (or fuel) that results in emitting harmful gases to the environment that is separated in the air and water. Researchers have conducted researches to increase projects that will generate clean and renewable energy. Usage of renewable energy via mankind is in continuous progress such as solar energy, bioenergy, ocean energy and wind energy. Wind energy waste while the car moved was used to produce electric energy. In this paper, the usage of unused wind energy in vehicles was developed so that additional power for vehicles was enable via converting wind power into electric one. The wind turbine was assembled from a fan and transducer. Indoor test showed generation of different electric voltages when varying the ambient temperature. The main experiment was carried out so that the wind turbine was installed above the car; values of voltages in various speeds of the car were recorded. When two fans were used with different specifications, the consequence was a direct proportionality that changes the happened between voltages and car's speeds. A comparison between the two fans showed that: the fan with big blade dimensions was the best one to generate voltages. Finally, the high voltages were generated in low temperatures. These results reveal that we can avail from wind energy to supply vehicles with electricity as long as vehicles move along the way.

\section{INTRODUCTION}

In the last few years, there has been a growing interest in technological alternatives to reduce $\mathrm{CO}_{2}$ emissions from power plants and factories to the atmosphere including: 1) usage of less carbon-intensive fuels, for example natural gas instead of coal; 2) increasing the use of renewable energy sources or nuclear energy sources, which produce little $\mathrm{CO}_{2}$; and 3) capturing $\mathrm{CO}_{2}$ [1]. Most of the researches on renewable energy technologies focus on their land requirements and the potential environmental and social impacts. 
Although renewable energy technologies often cause fewer environmental problems than fossil energy systems, they lead to new conflicts. On a global scale, the environmental benefits of renewable energy are enormous, and do not dispute their significant contributions to reducing global greenhouse gases emissions. However, the benefits are less clear at a local scale. Due to tapping more diffuse forms of energy, these technologies require greater areas of land [2]. Previous research has demonstrated that the use of renewable energy sources is a key strategy for reducing greenhouse gases. As the source of hydro, biomass or geothermal energy is limited in many countries, wind power and solar photovoltaic (PV) play an increasing role [3].

Many previous studies have developed techniques to generate electric power from wind turbines, even though, much has to be done. Humans have used energy from the wind for centuries. Used by the Europeans as early as 900 years ago, wind was used to grinding grain and manufacturing goods, wind powered ships that helped open up new region, spurring international trade.

Wind energy is increasing and could become a major source of electricity in the coming years because wind is widely available and often abundant in many parts of the world. There are large resources found on every continent. The utilization of the highest sites in the world's windiest locations could theoretically provide 13 times more electricity than is currently produced worldwide, according to the World Watch Institute at Washington.

Despite the advantages of wind turbines and their energy source, the wind, has a negative impact, wind energy is an abundant and renewable resource. The wind will not run out in the foreseeable future, unlike oil and natural gas. Small-scale wind energy could also help reduce our reliance on low and expensive oil supplies of oil if wind power electricity is used to operate electric cars, electric trucks and hybrids, resulting in the displacing of gasoline that is being refined from oil. Wind arises from the movement of horizontal air across the Earth's surface. All winds are produced by variations in air pressure between two regions. Variations in pressure result from differential heating of the surface of the Earth. Heating, of course, is caused by sunlight striking the Earth's surface. Like most other forms of energy in use today, even coal, oil and natural gas, wind is a product of sunlight solar energy. Some wind advocates, refer to wind as "the other solar energy" or "secondhand solar energy [4].

There are mainly two types of wind turbine: horizontal axis and vertical axis. The horizontal axis wind turbine (HAWT) and the vertical axis wind turbine (VAWT) are classified or differentiated by the axis of rotating of the shafts [5].

Modern wind turbines connected to the commercial network have evolved from small and simple machines to large and highly sophisticated machines. Both technological developments have supported scientific and engineering expertise and progress, as well as improved computational tools, design standards, manufacturing methods, and operating and maintenance procedures. Generating electricity from the wind requires that the kinetic converted the energy of moving air to electric energy, and the challenge of engineering for the wind industry is to design wind turbines and power plants in terms of cost effectiveness. Although a variety of turbines have been investigated, the commercially available turbines are primarily horizontal axis machines with three blades installed in the wind direction of the tower, in order to reduce the standard cost of wind power.

The development of the design of wind turbines, improved design and testing methods has been codified in International Electro Technical Commission Standards [6].

Researchers have registered a patent for a wind energy capturing device for moving vehicles including a wind turbine powered electrical power generator for installation on the roof of a moving vehicle such as a truck cab or tractor. The invention takes advantage of the powerful wind force generated by the vehicle moving on the road at moderate to high speed impinging against the wind deflector mounted on the truck cab or tractor. This otherwise "wasted" wind energy is captured and directed to the face area of the rotor blade, rotating the turbine, which, in turn, drives the generator to generate electricity [7]. In this paper one select two turbines with different specifications and conducted indoor and outdoor experiments, These experiments propose to avail from wind energy to generate electricity for electric vehicle. 


\section{METHODOLOGY}

\subsection{The Theoretical Model}

The power generated by wind is given by

$$
V I=P=\frac{\pi}{\delta} K_{\circ} \rho D^{2} v^{3}
$$

With

$K_{\circ}=$ conversion coefficient;

$\rho=$ air density;

$D=$ fan blade diameter;

$v=$ wind speed;

$V=$ generated voltage;

$I=$ generated current.

The air density $\rho$ is known to decrease upon increasing temperature $T$. this physical fact can be theoretically realized by bearing in mind that the decrease in density due to the temperature effect is related to the fact that, increasing temperature $T$, increases the spacing $x$ between successive atoms or molecules according to the phonon model relation [8]

$$
x=\frac{g k t}{c^{2}}
$$

where the restarting force $F$ takes the form

$$
F=-c x+g x^{2}
$$

With $K$ standing for Boltzmann constant, whereas $c$ and $g$ are stiffness parameters respectively.

In view of Equation (1) and (2), the density $\rho$ and generated voltage $V$ are given by

$$
\rho=\frac{m}{x^{3}}=\frac{m c^{3}}{g^{3} k^{3} T^{3}} \approx C_{1} T^{-3}
$$

where $m$ is the air mass enclosed in a volume $x^{3}$ [9].

Thus

$$
\begin{aligned}
V & =\frac{\pi}{8 I} k_{\circ}\left(c_{1} T^{-3}\right) D^{2} v^{3} \\
& =c_{2} T^{-3}=\frac{c_{2}}{T^{3}}
\end{aligned}
$$

where all parameters other than temperature are assumed to be constant. Thus the $V-T$ curve can be displayed in Figure 1

The relation between speed $v$ and voltage $V$, can be found from Equation (1) to be

$$
\begin{aligned}
V & =\frac{\pi}{8} \frac{k_{\circ} \rho}{I} D^{2} v^{3} \\
& =c_{2} v^{3}
\end{aligned}
$$

where the parameters other than $v$ are assumed to be constant, this relation can be displayed graphically in Figure 2.

\subsection{Apparatus and Equipment}

We carried out two experiments in which we used the following apparatuses and equipment's: Wires, two fans, a car, trestle "support", voltmeter, thermometer, heater, a pump of air $750 \mathrm{w}$, transducer 12 volt/Ac. 


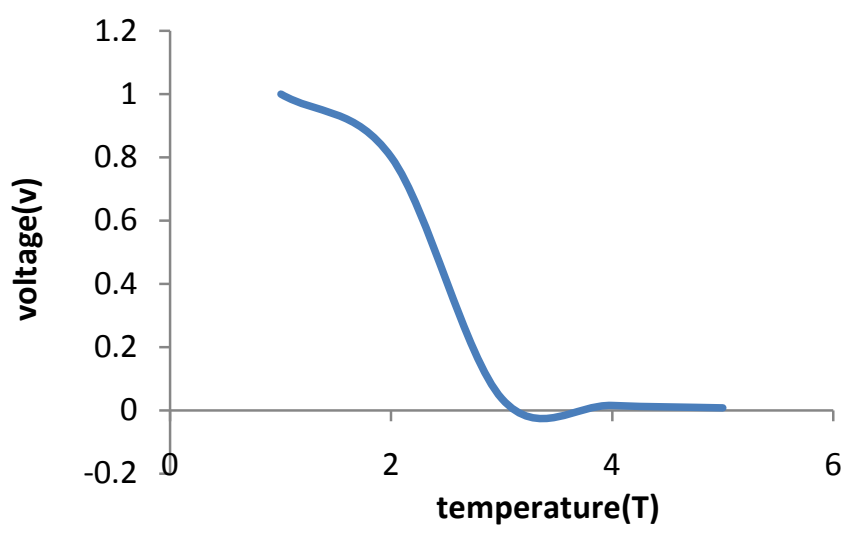

Figure 1. Relation between applied voltage $\mathrm{V}$ and air temperature $\mathrm{T}$.

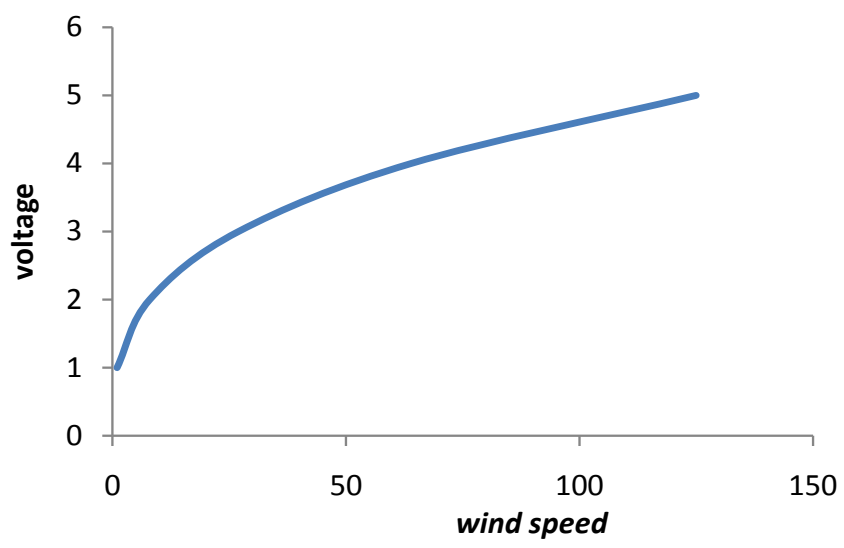

Figure 2. Relation between wind speed $v$ and generation voltage $\mathrm{V}$.

\subsection{Experiments}

In the first experiment we measured the length and width of the wind turbine fans, and then the fan and the power adapter were combined to convert wind energy into electrical energy. In the indoor test the power generation was recorded for different ambient temperatures of the room, whence a heater was used to change room temperature. In the second and main experiment the wind turbines were installed above the vehicle. The power generation, i.e. voltages values were recorded at different speeds of the vehicle.

\subsection{The Results}

\subsubsection{The First Experiment}

The following are records of the first experiment, where Table 1 shows the dimension records of the used fans, and the followed two graphs show the power generation in different temperatures.

1) Transducer with the large blade of fan.

2) Transducer with the small blade of fan.

\subsubsection{The Second Experiment}

The following two graphs show the power generation in different speed of car.

1) $V_{\circ}=2.2$ volt

*Transducer with the large blade of fan. 
Table 1. Specifications of the fans.

\begin{tabular}{ccccc}
\hline Number of the fans & $\begin{array}{c}\text { Number of the } \\
\text { blades }\end{array}$ & $\begin{array}{c}\text { The length/cm } \\
\pm 0.01\end{array}$ & $\begin{array}{c}\text { Maximum of width/cm } \\
\pm 0.01\end{array}$ & $\begin{array}{c}\text { Minimum of width/cm } \\
\pm 0.01\end{array}$ \\
\hline 1 & 3 & 16.9 & 17 & 4.5 \\
2 & 3 & 17.4 & 8.6 & 7.5 \\
\hline
\end{tabular}

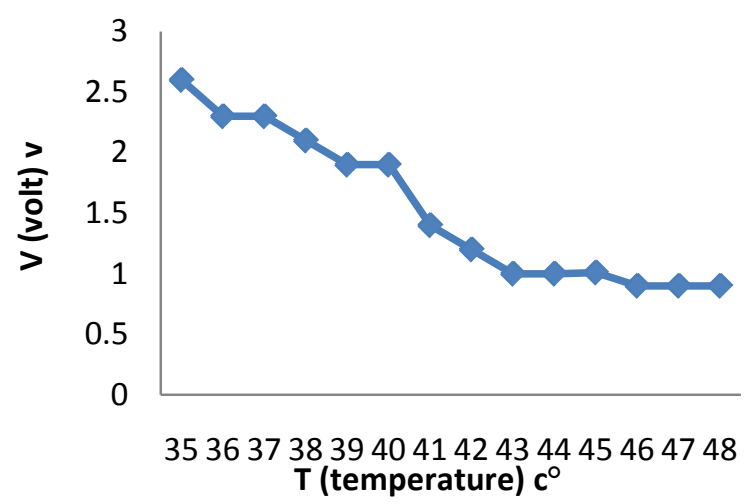

Figure 3. Temperature against volt for transducer with the large blade of fan.

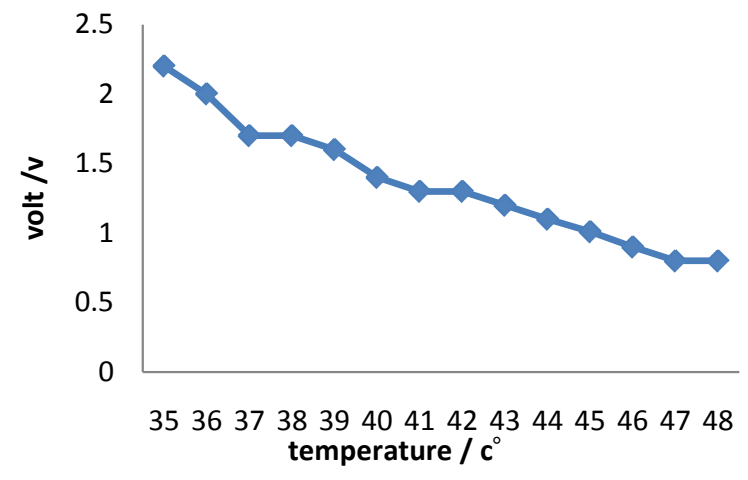

Figure 4. Temperate against the volt for transducer with small blade of fan.

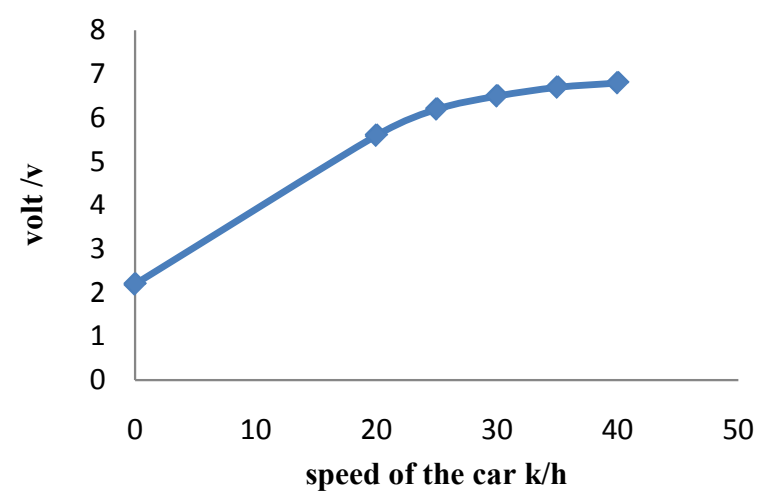

Figure 5. The speed against the volt for transducer with the large blade of fan. 


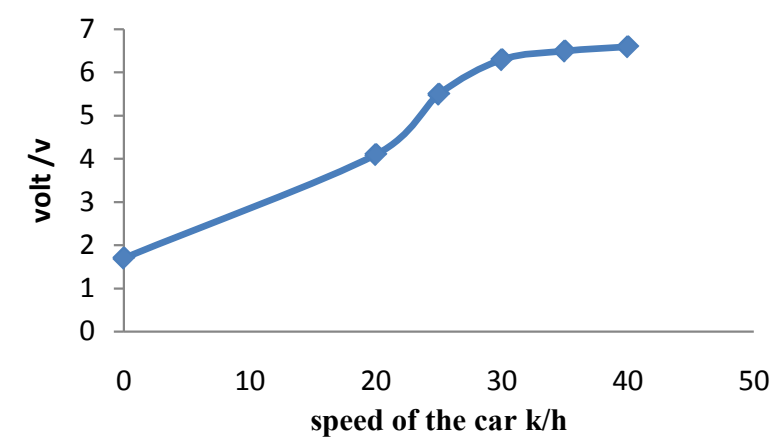

Figure 6. The speed against the volt for transducer with the small blade of fan.

\section{2) $V_{\circ}=1.7$ volt}

${ }^{\star}$ Transducer with the small blade of fan.

\section{DISCUSSION}

In the previous section of result Table 1 it showed measurements of blade dimensions for two fans; different dimensions mean different resistant to air that effect voltage generation of the wind turbine. In Figure 3 and Figure 4 the plot of voltage against temperature $/ c^{\circ}$ for the two fans, respectively were shown, and an inverse proportionality relation between voltage and temperature $/ \mathrm{c}^{\circ}$ has been observed. These empirical relation conforms with the theoretical relation displayed in Figure 1. It is also interesting to note that large blade fan voltage is higher than small one. This come from the proportionality of voltage $V$ with blade diameter D. In Figure 5 and Figure 6 the plot of voltages against speed of car for two fans, respectively were shown, and a direct proportionality relation between voltage and speed of a car has been observed. This relation agrees with the theoretical relation display in Figure 2. When using the fan with large blade dimensions, the voltage value was found to be equal to: $2.2 \mathrm{v}$, i.e. when the vehicle was in static state. This voltage results from free wind speed. It however when the vehicle started to move the value changed to: $5.6 \mathrm{v}$ for vehicle speed of $20 \mathrm{k} / \mathrm{h}$. This results from the fact that the wind speed increases due to the car motion. Thus $v$ increase according to Equation (1) at higher speed the voltage tend to remain fixed. this is similar to what happened in a small bladedimension fan. It is also very interesting to note that the voltage of large blade is higher than that of the smaller are due to the effect of radius according to Equation (1).

\section{CONCLUSION}

A comparison between the two fans showed that the fan with large dimensions blade was the best one to generate voltages, moreover, fans can generate high voltage at low temperatures. These results agree with theoretical models. It also reveals that one avails from wind energy to supply more electricity to vehicles as long as vehicles move along the way. One recommends that this experiment should be done using more fans and connect them with different transducers and connect them with batteries and take values of voltages and currents. The effect of change of dimensions of fans' blades, on the wind energy transducer performance, should be also studied.

\section{REFERENCES}

1. Energy, E.A.H. (2018) Carbon Capture and Sequestration in Power Generation: Review of Impacts and Opportunities for Water Sustainability. Sustainability and Society, 8, 6 .

2. Peker, Z. Integrating Renewable Energy Technologies into Cities through Urban Planning: In the Case of Geothermal and Wind Energy 2005, the Graduate School of Engineering and Science of Zmir Institute of Technology ZMR. 
3. Zerrahn, A., Schill, W.-P. and Kemfert, C. (2018) On the Economics of Electrical Storage for Variable Renewable Energy Sources. arXiv preprint arXiv. 1802.07885

4. Chiras, D. (2010) Wind Power Basics. Vol. 978-0-86571-617-9.

5. Al-Shemmeri, T. (2010) Wind Turbines.

6. Ottmar Edenhofer, R.P.-M., Sokona, Y., Eickemeier, K.S.P., et al. (2012) Reconciling Top-Down and Bottom-Up Modelling on Future Bioenergy Deployment.

7. Vu, T.H. (2005) Wind Energy Capturing Device for Moving Vehicles.

8. Saleh, A.S. Principles of Solid State Physics 2013: DAR SAFA.

9. Luth, H.I.H. (2003) Solid-State Physics: An Introduction to Principles of Materials Science. Springer-Verlag berlin Heidelberg, New York, Vol. 1.2, 87. 